\title{
Vaginal fibro-epithelial polyp as cause of postmenopausal bleeding: office hysteroscopic treatment
}

\author{
Maurizio Guida • Attilio Di Spiezio Sardo • \\ Chiara Mignogna $\cdot$ Stefano Bettocchi $\cdot$ Carmine Nappi
}

Received: 5 May 2007 / Accepted: 4 July 2007 /Published online: 17 August 2007

(C) Springer-Verlag 2007

\begin{abstract}
We report on the case of a 72-year-old woman who underwent office hysteroscopy following an episode of postmenopausal bleeding. A vaginal fibro-epithelial polyp was diagnosed and removed by means of a 5 Fr bipolar electrode inserted through the operating channel of a $5 \mathrm{~mm}$ continuous flow office hysteroscope.
\end{abstract}

Keywords Hysteroscopy · Office · Vaginal polyp

Fibro-epithelial polyp

\section{Introduction}

When an organic cause of postmenopausal bleeding is suspected, a uterine or cervical lesion is usually searched for. Vaginal lesions represent an unusual, often underestimated, cause of postmenopausal bleeding. Among vaginal lesions, the fibro-epithelial polyp (FP) represents a rare benign growth that should not be mistaken for a malignant growth, especially embryonal rhabdomyosarcoma [1].

\footnotetext{
M. Guida $\cdot$ A. Di Spiezio Sardo $(\bowtie) \cdot$ C. Nappi

Department of Gynecology and Obstetrics and Pathophysiology

of Human Reproduction, University of Naples Federico II,

Via Pansini 5,

Naples, Italy

e-mail: cdispie@tin.it

S. Bettocchi

Department of General and Specialistic Surgical Sciences,

Section of Obstetrics and Gynecology, University of Bari,

Bari, Italy

C. Mignogna

Department of Biomorphologic and Functional Sciences, Pathology Section, University of Naples Federico II,

Naples, Italy
}

\section{Case}

We report on the case of a 72-year-old woman who underwent office hysteroscopy following an episode of postmenopausal bleeding. The study was eventually approved by our Institutional Review Board.

Hysteroscopy was performed by a vaginoscopic approach (without speculum and tenaculum) using a $5 \mathrm{~mm}$ continuous flow office hysteroscope (Bettocchi Office Hysteroscope size 5; Karl Storz, Germany) with a $30^{\circ}$ grade optic and an incorporated $5 \mathrm{Fr}$ working channel. Normal saline solution was used for vaginal and uterine distension.

After a thorough inspection of the vagina, a polypoid lesion was detected in the proximal portion of the vagina near to the posterior cervical lip. The lesion was reddish, $1 \mathrm{~cm}$ in size, and with the appearance of a small "cauliflower" (Fig. 1). The uterine cavity and the endocervical canal showed no abnormalities.

The vaginal lesion was resected by means of a $5 \mathrm{Fr}$ Twizzle bipolar electrode (Gynecare; Ethicon, NJ, USA) inserted through the operating channel of the hysteroscope. The electrode was connected through a cable with a versatile electrosurgical system dedicated to hysteroscopy [Versapoint Bipolar Electrosurgical System (Gynecare; Ethicon)]. No analgesic was required during or immediately after the procedure. The histological diagnosis was FP. At 6 months' follow-up the patient did not complain of any vaginal bleeding.

\section{Discussion}

FP is an uncommon hamartomatous or benign neoplastic polypoid mass of the vagina, evoking a level of interest in 
Fig. 1 a Endoscopic and b macroscopic appearance of the vaginal fibro-epithelial polyp
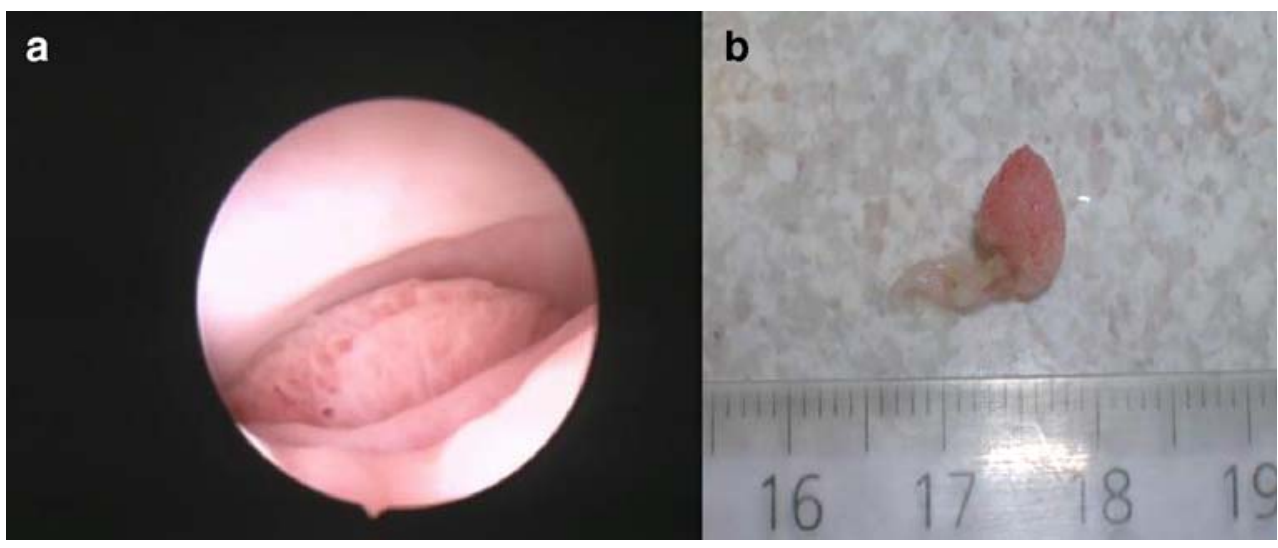

pathologists disproportionate to its frequency or significance. The mean age at diagnosis is approximately 40 years, with an age range varying from that of the newborn child to 77 years. The lesions are usually asymptomatic and are discovered incidentally, during pelvic examination, on the lateral wall of the lower third of the vagina [2].

Rarely, they can be associated with abnormal uterine bleeding, mostly after sexual intercourse. No report of FP as a cause of postmenopausal bleeding is available in the international literature.

The classical surgical resection of such lesions consists of excision by scissors after the application of a Kelly or Kocher forcep to prevent any blood loss. The availability of smaller diameter hysteroscopes with working channels and continuous flow systems, and the advent of bipolar electrosurgical technology, makes it possible to diagnose and eventually treat such benign vaginal lesions in the outpatient setting and also to diagnose and treat postmenopausal patients who might otherwise require general or local anesthesia [3, 4]. A vaginoscopic approach is imperative to obtain an appropriate vaginal distension and to identify any lesion in the vaginal cavity $[5,6]$.

\section{References}

1. Robboy SJ, Anderson MC, Russell P (2002) Pathology of the female reproductive tract. Churchill Livingstone, 4th edn, pp 84-85

2. Kurman J (2001) Blaustein's pathology of the female reproductive tract. Churchill Livingstone, 5th edn, pp 174-175

3. Bettocchi S, Nappi L, Ceci O, Selvaggi L (2003) What does 'diagnostic hysteroscopy' mean today? The role of the new techniques. Curr Opin Obstet Gynecol 15:303-308

4. Bettocchi S, Ceci O, Di Venere R, Pansini MV, Pellegrino A, Marello F et al (2002) Advanced operative office hysteroscopy without anaesthesia: analysis of 501 cases treated with a 5 Fr. bipolar electrode. Hum Reprod 17:2435-2438

5. Bettocchi S, Selvaggi L (1997) A vaginoscopic approach to reduce the pain of office hysteroscopy. J Am Assoc Gynecol Laparosc $4: 255-258$

6. Paschopoulos M, Paraskevaidis E, Stefanidis K, Kofinas G, Lolis D (1997) Vaginoscopic approach to outpatient hysteroscopy. J Am Assoc Gynecol Laparosc 4:465-467 